\title{
CALDERÓN DE LA BARCA Y TOLEDO
}

\author{
JAIME COLOMINA TORNER \\ Real Academia de Bellas Artes \\ y Ciencias Históricas de Toledo
}

\section{DOCUMENTOS INÉDITOS}

En el Año calderoniano, ya finalizado, la prensa ha puesto de relieve frecuentemente aspectos varios de la rica personalidad y producción literaria de Calderón. Una de estas facetas, menos conocidas, podría ser su relación con Toledo. Para darlo a conocer la R. Academia de B. A. y C. Históricas de esta ciudad y el Cabildo de la catedral organizaron un acto cultural en honor del dramaturgo el 16 de junio del 2000. Tuvo lugar en el mismo recinto de la Capilla de Reyes, en la que él fue capellán desde 1653 hasta su muerte.

Pedro Antonio Calderón de la Barca y Henao nació en Madrid el 17 de enero de 1600. Su abuelo paterno, Pedro, se había casado en Toledo con Isabel Ruiz, de la ilustre familia de artesanos espaderos, «los Ruiz». Dos tías paternas del poeta ingresaron a fines del siglo XVI en el convento toledadano de santa Clara; en 1612 ingresaría también en él su hermana Dorotea, dos años mayor que Pedro. Y, al parecer, trajeron asimismo al convento en 1613 a su hermanita Antonia María, de seis años, cuando el padre viudo se volvió a casar este mismo año con Juana Freyre. La niña murió pronto.

Transcribo ahora dos tipos de documentos, que estimo inéditos; unos que se refieren a las Ordenes sagradas que recibió, y otro que pudiera aclarar el enigma del primer fracaso que sufrió al pretender ser capellán de Reyes de Toledo.

\section{I}

Algún biógrafo se muestra dubitativo sobre los estudios eclesiásticos del joven Calderón. Los documentos que transcribo ahora, hallados este mismo año en el archivo diocesano de Toledo, despejan cualquier duda. 


\section{LEGAJO SOBRE SAGRADAS ÓRDENES (1614)}

Expediente que comprende su solicitud y unos testimonios.

Nota al encabezamiento:

«don $\mathrm{p}^{\circ}$ para corona. Don Joseph no muestra fe del bautismo. muestrela» «don $\mathrm{p}^{\circ} \mathrm{y}$ don Jusepe calderon delabarca ermanos y vecinos de la villa de madrid presentamos ante VI esta ynformacion de nuestra limpieza y genealogia para efeto de nos ordenar. para dicho don $\mathrm{p}^{\circ}$ de corona y grados y a dicho don Jusepe de corona. A Vp suplico lo mande ver y darnos certificacion para ser ordenados

Pedro Calderon». (firmado)

«En T. Dia 12 de marco de 1614. Las informaciones de limpieza estan buenas para don pedro y don Josef calderon hermanos. El don Josef no a presentado fe del bautismo. a don pedro sele de certificacion para corona sola».

El mismo dramaturgo recordará festivamente hacia sus 40 años esta clerical tonsura de su adolescencia:

«El de Troya me ordenó - de la primera tonsura - de cuyas ordenes solo - la coronilla me dura» (aludiendo quizá a una incipiente calvicie)

Pero he descubierto también otro expediente de 37 años más tarde con la solicitud de puño y letra de Calderón pidiendo ya las Ordenes mayores. Acompañan a la solicitud en el expediente otros 14 documentos (testimonios, etc.)

«En $t^{\circ} 22 \mathrm{~m}^{\circ}$ de 1651

Ilm. $S$

(Admitese el Breve y desele letras para grados y (Epistola esta dispensado de intersticios.

Don Pedro Calderon delabarca Caballero dela orden desantiago digo $=$ que por los años deseisciento y diez; hasta doce $=$ me ordene en esta ciu.d de primera tonsura cuyos titulos con la dilacion de tanto tiempo seme anperdido. Y que no aviendo como no ay archibo en ella delas ordenes; aunque e acudido abeces con las matriculas he hallado algunas enpoder delos herederos de algunos secretarios que lo eran por entonces; no e hallado Racon de mi partida. $\mathrm{Y}$ que aunque quiera dar dello ynformacion no son faciles de hallar testigos que de quarenta años a esta parte puedan deponer indibidualmente deque me vieron ordenar. Supp.co Avtil. mande quesemetome mi declaracion y juramento en toda forma y seaya de estar al credito dello. Para que no por un accidente tan casual como perderse un titulo deje oy de pasar a tanperfecto estado como el del sacerdocio para acabar enel mi vida con mas quietud y seguridad demi conciencia; o Vme. provea en este caso de dar Remedio mas conbeniente para no embarracar tan buen proposito.

Don Pedro Calderon delabarca»

Hay una nota marginal: «Jure Don Pedro q. esta ordenado de Corona» 
Un segundo documento contiene el mandato del cardenal Sandoval, de Toledo, al párroco del El Salvador, de Madrid, para que se hagan las publicatas en su iglesia sobre don Pedro. Se fecha el 28 de febrero de 1651. En el dorso de este documento se halla la respuesta del párroco, con fecha 9 de marzo, diciendo, entre otras cosas:

«el domingo cinco deste pr.te mes de Marco de mill y seis. ${ }^{\circ}$ y cinq. ta y uno en conformidad del mandam.to desta otra parte al tiempo de la misa mayor estando el correg.or justicia y regim.to desta dicha villa y otras muchas personas para oyr el sermon publique dcho $\mathrm{m}^{\circ}$ y lo hize notorio en alta voz como el dcho don Pedro Calderon sequeria ordenar de Epistola, que si havia alguna pers.a que lequisiera poner algun ympedim.to loviniesse manifestando $=\mathrm{y}$ assi por el conocim.to que tengo con dcho don Pedro como por la publica voz y fama que ay enesta villa y parrochia es tenido y tengo al don Pedro Calderon por persona principal y qualificada de buen xristiano de buena vida y costumbres y quees muy frequente al servicio del culto divino y alos santos sacram. tos con el de la penitencia $=\mathrm{Y}$ assimesmo certifico quehasta oy dia dela fcha noha resultado ympedim.to alguno, y lo firmo en Madrid a nueve de Marco del mill y seis.os y cinq. y uno»

Y a pie de página el notario da fe de que la firma del licenciado Esteban Alvarado es auténtica.

Otros dos documentos transcriben sendas certificaciones del bautismo y confirmación de Don Pedro, que omito por ser ya conocidas. En otro documento (pergamino) se contienen las dispensas de posibles impedimentos y de intersticios para las Ordenes. Lo firma el 10 de agosto de 1651 el Delegado «a latere» del papa Inocencio X en España.

Uno de los documentos, firmado por Calderón y el notario Antonio f. de Ribera, recoge el juramento que hizo el primero afirmando su clerical tonsura:

«En la ciudad de toledo a veinte y dos dias del mes de marco demil y seis. ${ }^{\circ}$ y cinquenta y un años yo el presente notario secretario Recibi juram.to en forma de derecho de don pedro Calderon delabarca Caballero del abito de Santiago dela villa de Madrid estando ael presente enestaciudad. El qual se yco por el abito de su Religion puestalamano enelpecho y socargo del prometio de decir verdad y siendo preguntado dijo que esta ordenado de prima tonsura que le ordeno el Señor don Melchor de Soria y Vera que fue obispo de Troya en ordenes generales desde el año de seisc. ${ }^{\circ}$ y diez astael de hace poco mas o menos y esto es verdad so cargo de juramento y es dehedad de cinquenta años y lo firmo».

Otro nos detalla cómo Calderón pasa a ser capellán de la Memoria fundada por su abuela doña Inés de Riaño:

«En $\mathrm{T}^{\circ} 29$ de nob. del 50

Miguel Manuel (?) en n.e de don Pedro Calderon delabarca caballero del abito de Santiago = digo que el susodcho trata de ordenarse de orden sacro Y para 
este efecto don Pedro Ladron de Guevara comomarido de Dña Ana de henao y como Patrono quees de lamemoria y patronato que fundo Dña Ines de Riaño viuda de Diego de Henao y Abuela del dcho mi parte le ha nombrado por cumplidor y Capellan dela dcha memoria porescritura otorgada en dos de noviembre deste año deque hago demostracion. Y porque el dcho Don Pedro Calderon mi parte esta llamado por la dcha fundadora en el testamento debajo de cuya disposicion fallecio y en el que fundo la dcha memoria de misas, como del mismo testamento parece como tambien hago demostracion $\mathrm{Y}$ la dcha memoria esta sita en la iglesia de San Salvador de la Villa de Madrid, en la capilla del señor San Joseph Y esta fundada sobre unas casas Principales que dcha fundadora tenia y le pertenecian en la dcha Villa de Madrid en dcha parroquia de San Salvador y calle dela plateria que rrentan trecientos ducados en cada un año pagadas las cargas $\mathrm{Y}$ la dcha cantidad es congrua bastante para el dcho mi parte $=$ Atento aloq. aVS pido y sup.co que avida informacion de cómo todo lo referido es cierto y verdadero declare era titulo bastante para que se pueda ordenar de orden sagrado el dcho Don Pedro Calderon delabarca la dcha memoria Capellania y patronato de misas y que para ello seleden los despachos necesarios pido insis.ment.

(Firma sólo con su apellido)

Otros documentos del legajo contienen testimonios y otros datos sobre la relación de Don Pedro con esta capellanía fundada por su abuela en Madrid.

\section{OTRO TEMA CALDERONIANO}

¿Por qué fracasó su intento de ser capellán de Reyes en Toledo el año 1651 ?

Lo recuerda él mismo con cierta amargura en carta escrita al patriarca de las Indias (primavera de 1652), quejándose de que se le critique por seguir escribiendo después de ser sacerdote y dice:

«hasta que habiendo puesto los ojos en una pretension (ser capellán de Reyes) que cabe en los limites de mi esfera no desguarnecida de servicios propios y heredados; despues de publicada la merced me la ha retirado la objecion de no se quien, que juzga incompatibles el sacerdocio y la poesia».

Se suele acusar al mismo patriarca de las Indias D. Alonso, Capellán Mayor de Reyes. Así, por ejemplo, el conocido biógrafo E. Cotarelo y Mori, Ensayo sobre la vida y obra de D. Pedro Calderon de la Barca: «Una capellanía...en Toledo había ya solicitado y obtenido en 1651; pero le fue retirada la merced real por el patriarca de las Indias don Alonso Pérez de Guzmán, como capellán mayor de los Reyes Nuevos y gran enemigo de las representaciones de teatro, fundándose en que Calderón era indigno del cargo por escribir comedias» (p. 287) 
No pudo ser así, porque leo en las Actas de la Capilla, que estoy catalogando, que dicho señor no empezó a ser capellán mayor de la misma hasta el verano de 1652. Sin embargo, he hallado un acta misteriosa, que pudiera ser la respuesta a esa duda de Calderón. Dice así:

\begin{abstract}
«El veinte y ocho de julio del seiscientos cinquenta y un años los Sres. Don Gonzalo de Salazar, Sr. Obispo de Troya y yo (el secretario D.Jacinto Castellvi) nos juntamos en conformidad del acto capitular del 5 del presente mes y año (en el que se determinaba se constituyese una comisión reducida para asuntos secretos y urgentes)... y se acordo que se assentase y escriviesse aquí la relacion delo q. se avia obrado en Mad. conlas Cartas q. se escrivieron a Su Magd. a su Rl Consejo de Camara y otras pers.as a quien fue a hablar de parte desta Rl Capilla el sr. D Fco. Molinet en orden a supplicar q. no selihiciese mer.d de placa de Cappellan en esta Rl Cappilla a cierta persona q. por algunas causas no seria decente, y redundaria en notorio deshonor della... Luego q. llego a Md. escrivio avisando q. la pretension dela parte estaba muy adelante...Fue dando noticia en todas las estafetas de las diligencias q. hacia, como fue hablar al Rey $\mathrm{n}^{\circ} \mathrm{Sr}$ y darle mem.l. con que consiguio decreto remitiendole al Cons. dela Cam.a. Dio Carta al Cons. dela Cam.a y al P. Confessor de su Magd. Y hablo tambien al Presdte. de Castilla D.Luis de Haro y otros Ministros. Con cuyas dilig-as. se consiguio averse suspendido el efecto de dicha merd. hecha al sujeto q.por justas causas nose nombra».
\end{abstract}

$\mathrm{Si}$, como parece probable, se referían a Calderón no resultaron profetas en lo del deshonor para la Capilla de Reyes. Pero, cuando dos años más tarde ingresó, de hecho, tras una actitud inicial algo recelosa, se mostraron buenos compañeros en la diaria convivencia de casi tres años. Relación con la Capilla que no se interrumpiría hasta la muerte de D. Pedro en mayo de 1681 . 